\title{
Risk factors of recurrence for resected T1aNOMO invasive lung adenocarcinoma: a clinicopathologic study of 177 patients
}

Fan Yang ${ }^{1}$, Kezhong Chen ${ }^{1}$, Yida Liao ${ }^{1}$, Xiao Li ${ }^{1}$, Kunkun Sun${ }^{2}$, Dongmei Bao ${ }^{2}$ and Jun Wang ${ }^{1 *}$

\begin{abstract}
Background: This study aimed at identifying risk factors of recurrence for completely resected pathologic T1aNOMO lung adenocarcinomas.

Methods: We reviewed the records of 177 T1aNOMO invasive adenocarcinoma patients, and re-classified achieved surgical specimens according to the new International Association for the Study of Lung Cancer, American Thoracic Society, and European Respiratory Society (IASLC/ATS/ERS) lung adenocarcinoma classification. Impact on recurrence-free survival (RFS) for age, gender, smoking history, lymphovascular invasion (LVI) and new classification was analyzed by log-rank test and Cox regression. Two existing prognostic grouping schemes of new classification were compared, and subsequently, the correlation of high-grade group in the better prognostic grouping model with clinical data was investigated statistically.

Results: The 5-year recurrence-free rate was $83.7 \%$. The LVI and new adenocarcinoma classification were significantly associated with 5-year RFS ( $P=0.012 ; P=0.022$, respectively). The designation of papillary predominant subtype in the low-grade group, along with lepidic- and acinar predominant subtype had more prognostic significance than the model of combining papillary-, solid- and micropapillary predominant subtypes as the high-grade group $(P=0.005$ versus $P=0.181$ ). This high-grade group has increased risk of recurrence in a multivariate Cox regression (adjusted HR $2.815,95 \% \mathrm{Cl}: 1.239$ to $6.397, P=0.013$ ), and is associated significantly more with male gender (adjusted OR 2.214, 95\% Cl: 1.050 to $4.668, P=0.037$ ), and, with borderline significance, the presence of LVI (adjusted OR 2.091, 95\% Cl: 0.938 to 4.662, $P=0.071)$.
\end{abstract}

Conclusions: Our results showed that the solid- and micropapillary predominant subtype of IASLC/ATS/ERS classification remains the only risk factor for post-operative recurrence of T1aNOMO adenocarcinomas, suggesting that they can be indicators of aggressive tumor behaviors.

Keywords: Lung adenocarcinoma, Recurrence, New classification, Solid predominant adenocarcinoma, Micropapillary predominant adenocarcinoma

\section{Background}

Lung carcinoma is one of leading causes of cancer death worldwide, and its incidence rate continues to increase [1]. Adenocarcinoma is the most common histologic type of lung cancer, especially among Chinese women [2]. The widespread use of computed tomography (CT) screening encouraged by positive results of the National Lung

\footnotetext{
* Correspondence: jwangmd@yahoo.com

'Department of Thoracic Surgery, Peking University People's Hospital,

11 Xizhimen Nan Ave, Beijing 100044, China

Full list of author information is available at the end of the article
}

Screening Trial is detecting more and more early-staged adenocarcinomas [3,4]. T1aNOM0 constitutes the earliest stage of invasive lung cancer. As the standard of care, follow-up and surveillance without adjuvant therapy are recommended after complete resection [5]. However, some patients experience recurrence and die of lung cancer. According to the seventh lung cancer staging project by the International Association for the Study of Lung Cancer (IASLC), T1a non-small cell lung cancer (NSCLC) has a 5 -year survival of about $80 \%$ [6]. Therefore, there

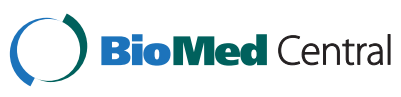

(c) 2014 Yang et al.; licensee BioMed Central Ltd. This is an Open Access article distributed under the terms of the Creative Commons Attribution License (http://creativecommons.org/licenses/by/2.0), which permits unrestricted use, distribution, and reproduction in any medium, provided the original work is properly credited. The Creative Commons Public Domain Dedication waiver (http://creativecommons.org/publicdomain/zero/1.0/) applies to the data made available in this article, unless otherwise stated. 
has been a need to identify these small but aggressive tumors for more careful follow-up and/or adjuvant therapy.

Many efforts have investigated the use of clinical, radiologic, and histologic factors to refine the prognosis of adenocarcinomas after surgical resection. Studies have reported prognostic significance of gender $[7,8]$, smoking history [9], tumor size [10], degree of differentiation [11], visceral pleural invasion [12], lymphovascular invasion (LVI) [13,14], ground-glass opacity/solid ratio [15], size of invasive tumor [16], maximum uptake on positron emission tomography (PET) scan $[10,15]$. Given the fact that prognostic factors of lung cancer may vary with tumor size [17], whether these factors have prognostic value in T1aN0M0 adenocarcinomas is still unknown.

Remarkable advances in understanding lung adenocarcinoma have led to a new classification system, sponsored by the IASLC, the American Thoracic Society (ATS), and the European Respiratory Society (ERS) [18]. Several independent studies have validated the prognostic significance of new adenocarcinoma histologic subtypes $[16,19,20]$, but little attention has been paid to T1a tumors after radical resection. However, previous studies of adenocarcinoma $\leq$ $2 \mathrm{~cm}$ failed to include new classification into the analysis $[13,21,22]$. The prognostic factors for completely resected T1aNOM0 adenocarcinomas are still an open question. It has been suggested that prognostic factors for lung cancer may vary with tumor size [17].

The main purpose of our study was to determine the risk factors for recurrence in a cohort of Chinese patients with radically resected invasive T1aNOM0 adenocarcinoma.

\section{Methods}

\section{Patients}

This study was approved by the Institutional Review Board of Peking University People's Hospital. Consent from patients was waived as this study is retrospective and no personal identifiable information was included in the manuscript. We performed a retrospective review of a prospectively maintained lung cancer database of all surgically resected NSCLC patients at our institution from January 2004 to September 2011. The inclusion criteria included complete resection by lobectomy with mediastinal lymph node dissection and a definitive pathologic confirmation of T1aNOM0 lung adenocarcinoma. Those patients with preinvasive or minimally invasive lesions defined by the new classification [18], or concurrent malignancy, or multiple tumors were excluded. Follow-up was performed on an outpatient basis at three-month intervals for the first two years and at six-month intervals thereafter. In all, 177 patients were included in this study.

\section{Parameters and histologic subtyping}

Data extracted from each patient's medical record included age, sex, smoking history, tumor size and tumor grading. Maximum uptake on PET scan was not chosen, because it is size-dependent and there is controversy regarding the value of PET scanning for peripheral clinical T1a lesions [23]. Measurements for percentage of groundglass opacity (GGO), which are proposed as an indicator for less invasive tumor [15], were not included in the present analysis.

All formalin-fixed surgical specimens were categorized according to the IASLC/ATS/ERS classification of lung adenocarcinoma [18]. Two pathologists reviewed all H\&Estained slides, recording the percentage of each histologic component in 5\% increments, and discussing until consensus was achieved. The predominant subtype was defined as the pattern found with the largest proportion [18]. The presence of lymphovascular invasion (LVI) was defined as the presence of aggregates of tumor cells inside vascular or lymphatic micro-vessels.

\section{Endpoint}

In the current study, recurrence-free survival (RFS) was defined as time interval from surgery to the time of diagnosis of first definite clinical or pathologic evidence of local recurrence or metastatic disease, lung cancerrelated death, or last follow-up. Patients were censored if they were alive with recurrence-free status at the time of the most recent follow-up or had died without documented recurrence. Overall survival was not an endpoint for this study. The interest comes from the success of epidermal growth factor receptor (EGFR) inhibitors, which improve the median survival of late-staged EGFR mutation-positive patients from about ten months with chemotherapy alone [24], to over thirty months [25]. Prognostic analysis of overall survival will be biased by predictive factors, such as EGFR mutation, which associates with female sex and the status of having never smoked [26].

\section{Statistical analysis}

The RFS was plotted by the Kaplan-Meier method, and differences in RFS were assessed using the log-rank test. Risk factors associated with RFS in univariate analysis with Cox proportional hazards model analysis with a $P$ value less than 0.10 were entered into a multivariate analysis. Correlation analysis of clinicopathologic variables with histologic subtype groups was performed by Logistic regression. A $P$-value less than 0.05 was considered statistically significant. Statistical calculations were performed using SPSS (version 16.0; SPSS, Chicago, IL, USA).

\section{Results}

\section{Patient characteristic}

Of the one hundred and ninety-eight patients who fulfilled the inclusion criteria, eight patients were excluded due to preinvasive adenocarcinoma, eight patients due to multiple tumors and five patients due to concurrent 
malignancy during the past five years. Finally, 177 patients were included in this study. The clinicopathologic features including age, gender, smoking history, tumor size, LVI and new IASLC/ATS/ERS classification are listed in Table 1. More patients were female (98 patients, $55.4 \%$ ) and the median age was 65 years (range 82 to 33 years). The median follow-up period was 44 months (range 7 to 89 months).

All specimens were confirmed as invasive adenocarcinomas and then re-classified according to the criteria of the IASLC/ATS/ERS classification of lung adenocarcinoma [18]. The most frequent histologic subtype in our cohort was acinar predominant, consisting of 58 cases (32.8\%) followed by lepidic predominant, comprising 45 tumors (25.4\%). Papillary-, micropapillary-, and solid predominant adenocarcinomas accounted for 37 (20.9\%), 19 (10.7\%), and $18(10.2 \%)$ specimens respectively (Table 1$)$. Variant adenocarcinomas were not found.

Table 1 Clinicopathologic characteristics of 177 patients with invasive T1aNOMO adenocarcinoma

\begin{tabular}{|c|c|c|c|}
\hline Variables & Number (\%) & $\begin{array}{c}\text { Five-year } \\
\text { RFS\% }\end{array}$ & $\begin{array}{c}P \text {-value by } \\
\text { log-rank test }\end{array}$ \\
\hline \multicolumn{4}{|l|}{ Age } \\
\hline$\leq 65$ & 97 & $83.7 \%$ & 0.520 \\
\hline$>65$ & 80 & $83.5 \%$ & \\
\hline \multicolumn{4}{|l|}{ Sex } \\
\hline Male & 79 & $84.1 \%$ & 0.855 \\
\hline Female & 98 & $83.4 \%$ & \\
\hline \multicolumn{4}{|l|}{ Smoking history } \\
\hline Never-smoked & 128 & $81.7 \%$ & 0.424 \\
\hline Smoker & 49 & $88.7 \%$ & \\
\hline \multicolumn{4}{|l|}{ Tumor size } \\
\hline$\leq 1 \mathrm{~cm}$ & 21 & $95.2 \%$ & 0.231 \\
\hline$>1$ to $\leq 2 \mathrm{~cm}$ & 156 & $82.2 \%$ & \\
\hline \multicolumn{4}{|l|}{ LVI } \\
\hline Absent & 135 & $87.5 \%$ & 0.012 \\
\hline Present & 42 & $72.1 \%$ & \\
\hline \multicolumn{4}{|l|}{ Histological grading } \\
\hline Well differentiated & 78 & $85.4 \%$ & 0.535 \\
\hline Moderately differentiated & 66 & $82.0 \%$ & \\
\hline Poorly differentiated & 33 & $83.0 \%$ & \\
\hline \multicolumn{4}{|l|}{ Predominant subtypes } \\
\hline Lepidic & 45 & $94.9 \%$ & 0.022 \\
\hline Acinar & 58 & $83.1 \%$ & \\
\hline Papillary & 37 & $91.9 \%$ & \\
\hline Solid & 18 & $67.4 \%$ & \\
\hline Micropapillary & 19 & $57.6 \%$ & \\
\hline
\end{tabular}

Abbreviations: LVI lymphovascular invasion, RFS recurrence-free survival.

\section{Survival analysis}

During the median follow-up period, 24 recurrences were documented, including 2 local recurrences and 22 distant metastases (with/without local recurrence). Of these recurrences, ten were confirmed pathologically, mostly by fine-needle aspiration or supraclavicular lymph node biopsy, and the remainder was defined by radiologic evidence. Five-year RFS was 83.7\% (Figure 1). Log-rank tests of each parameter showed that the presence of LVI was a significant predictor of 5 -year RFS $(72.1 \%$ versus $87.5 \%$, $P=0.012$ ). Adenocarcinoma classification was also significantly associated with risk of recurrence $(P=0.022)$. Lepidic predominant subtype had the highest 5-year RFS (94.9\%), followed by papillary predominant (91.9\%). The micropapillary predominant subtype had the lowest RFS (57.6\%), followed by the solid predominant (67.4\%). The acinar predominant subtype had a 5-year RFS of $83.1 \%$ (Table 1).

In order to increase statistical power, we combined predominant subtypes with similar survival into groups, as was done in previous studies [16,19,27-29]. However, the grouping schemes differ on the designation of papillary predominant tumors; whether it should be grouped as highgrade $[7,27,29]$ or intermediate-grade $[16,19,28,30,31]$. We compared both grouping schemes on our cohort. For model 1, the low-grade group included lepidic-, acinar-, and papillary predominant adenocarcinomas, while the high-grade group consisted of solid- and micropapillary predominant tumors. Regarding model 2, the papillary predominant was designated also as the high-grade group. Log-rank tests of both models showed designation of the papillary predominant into the low-grade group better stratified prognosis with respect to 5-year RFS ( $P=0.005$ for model 1 versus $P=0.181$ for model 2) (Figure 2). Model 1 of grouping was used for further analysis in this study.

We then performed Cox multivariate survival analyses. We included those factors that were significant in univariate survival analysis, namely, sex, LVI, and pattern groups. The analysis showed that the adenocarcinoma subtype grouping (model 1) remained significantly associated with RFS, with patients in the high-grade group having an increased risk of recurrence, compared with the low-grade group (adjusted hazard ratio (HR) 2.815, 95\% CI: 1.239 to $6.397, P=0.013$ ) (Table 2). LVI only showed borderline significance (adjusted HR 2.100, 95\% CI: 0.930 to $4.741, P=0.074$ ).

\section{Correlation of more aggressive subtypes with clinicopathologic variables}

Finally, we performed correlation analysis to explore the relationship between the clinicopathologic parameters and the adenocarcinoma prognostic grouping by logistic regression. Multivariate regression of significant variables in univariate analysis showed significant association of male 


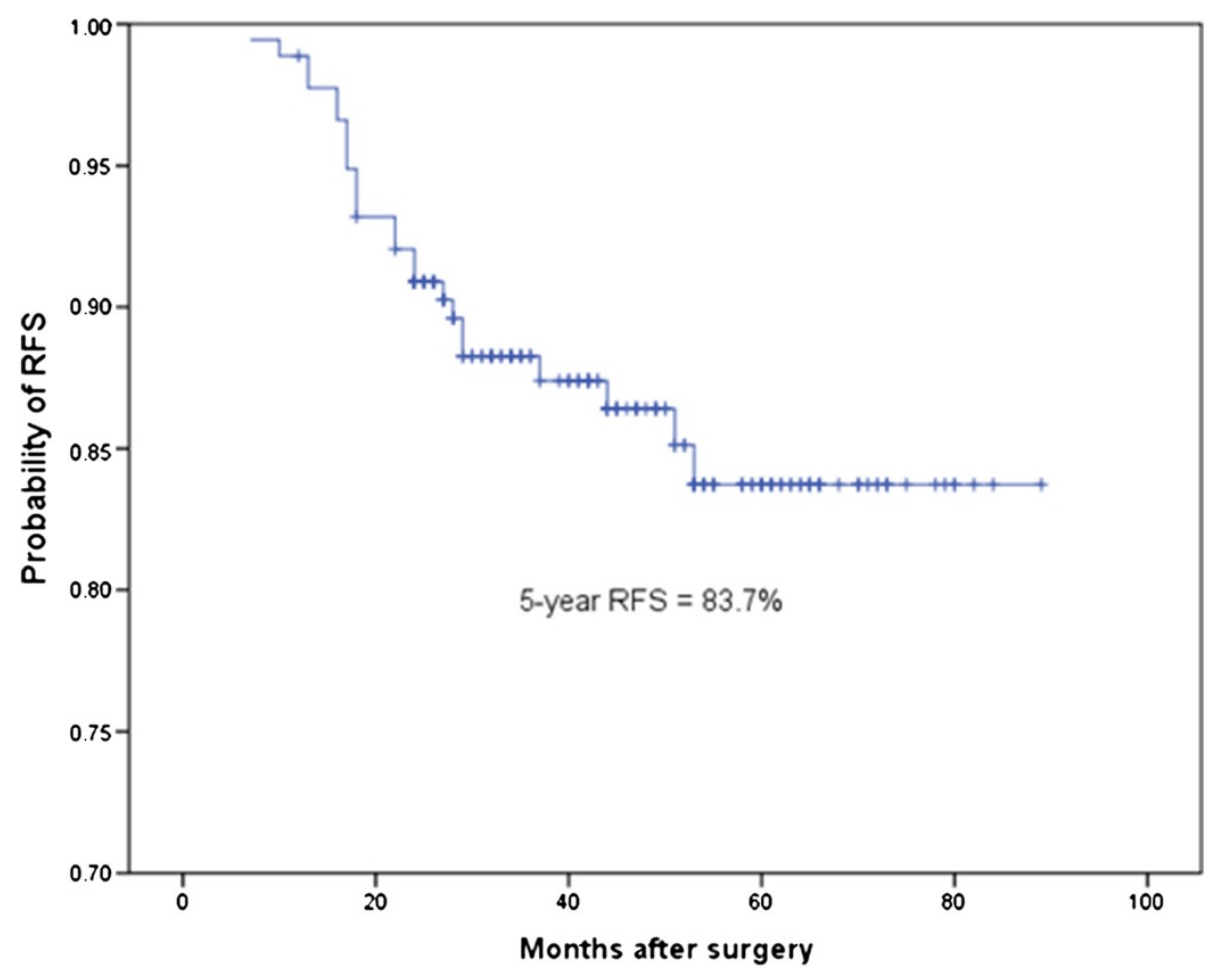

Figure 1 Recurrence-free survival (RFS) of all 177 patients with invasive T1aNOMO lung adenocarcinoma.
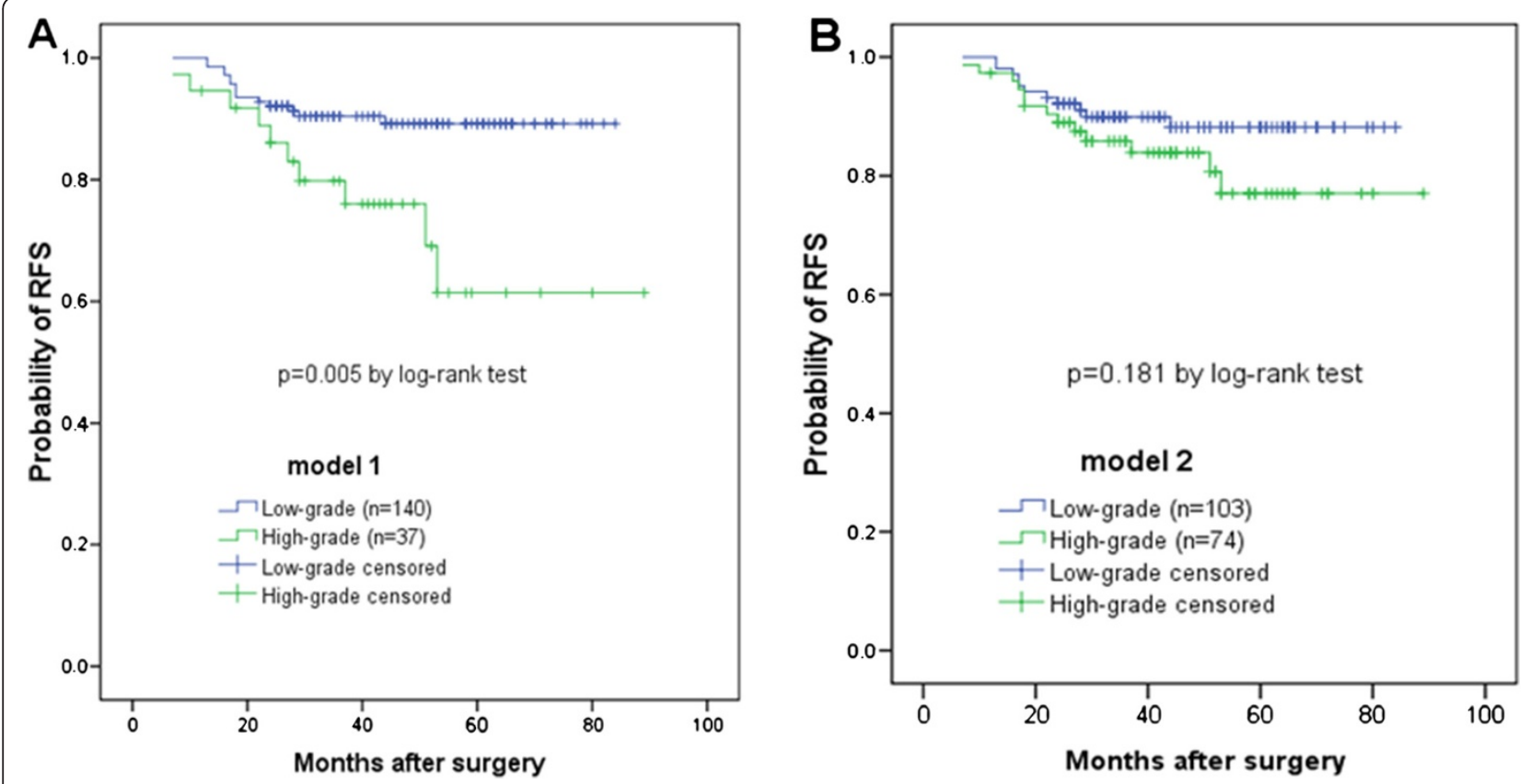

Figure 2 Probability of recurrence-free survival of different histologic prognostic groups. (A) In grouping scheme 1, the papillary predominant subtype was designated in the low-grade group, along with lepidic- and acinar predominant subtypes. The low-grade group had significantly lower probability of recurrence $(P=0.005)$. (B) Grouping scheme 2 combined papillary-, solid- and micropapillary predominant subtypes as the high-grade group. The difference of probability of RFS between the low- and the high-grade groups failed to reach statistical significance $(P=0.181)$. 
Table 2 Multivariate analysis for five-year recurrence-free survival (RFS)

\begin{tabular}{lccc}
\hline Variables & Univariate Cox, $\boldsymbol{P}$ & $\begin{array}{c}\text { Multivariate Cox, } \\
\text { HR (95\% Cl) }\end{array}$ & $P$ \\
\hline Age & 0.233 & & \\
Sex & 0.517 & & \\
Smoking history & 0.428 & $2.974(0.798$ to 11.078$)$ & 0.104 \\
Tumor size & 0.079 & $2.100(0.930$ to 4.741$)$ & 0.074 \\
LVI & 0.016 & & \\
Histological grading & 0.362 & $2.815(1.239$ to 6.397) & 0.013 \\
\hline Subtype grouping & 0.008 & &
\end{tabular}

sex with high-risk group (adjusted odds ratio (OR) 2.214, 95\% CI: 1.050 to $4.668, P=0.037)$. The statistical significance for LVI was borderline (adjusted OR 2.091, 95\% CI: 0.938 to $4.662, P=0.071$ ).

\section{Discussion}

To the best of our knowledge, the current study is the first clinicopathologic prognostic analysis of T1aNOM0, incorporating clinicopathologic and new IASLC/ATS/ ERS classification variables [13,22]. The only published study investigating the prognostic utility of the classification for patients with $\leq 2 \mathrm{~cm}$ adenocarcinomas focused on the association of the percentage of micropapillary component with recurrence, and between lobectomy versus limited resection. We carefully designed this retrospective study, trying to identify risk factors that can reflect accurately the behaviors of early-staged lung adenocarcinomas.

Because adenocarcinoma in situ (AIS), and minimally invasive adenocarcinoma (MIA) have $100 \%$ or near $100 \%$ disease specific survival after complete resection [18], they were excluded in our study of risk factors for recurrence. Visceral pleural invasion (VPI) was also excluded since it is not only determined by aggressiveness of tumor, but also by its anatomic location. Although one study which focused on adenocarcinomas $<2 \mathrm{~cm}$ found no impact of VPI on recurrence or survival [32], a nation-wide registry study confirmed the association of worse survival with VPI in NSCLC of all sizes [33], and the adverse impact of VPI was hypothesized as dissemination through parietal sub-pleural lymphatic drainage [34]. Moreover, we chose patients after radical lobectomy and lymph node dissection, so that surgical margin-related recurrence would not influence the analysis [35].

Our cohort of T1aNOM0 lung adenocarcinoma patients had a 5-year RFS of $83.7 \%$, similar to previous reports $[22,36]$. The distribution of IASLC/ATS/ERS subtypes varies considerably in the literature, which may have resulted from differences between geographical regions and ethnic populations (east versus west) [16,31], patient groups (all stages versus stage I) [29], and the expertise of the pathologists [37]. The frequency of lepidic predominant ranged from $26.7 \%$ reported by a Japanese study to $5.6 \%$ in a US cohort, while that for papillary predominant ranged from $40.9 \%$ to $4.7 \%$. The percentage of micropapillary ranged from $15.2 \%$ to 0 out of 191 adenocarcinomas in a Japanese study. In the current study, the most frequent histologic subtype was acinar predominant, comprising 58 out of 177 cases (32.8\%), followed by lepidic predominant, 25.4\%. Papillary-, micropapillary-, and solid predominant adenocarcinomas accounted for 37 (20.9\%), 19 (10.7\%), and 18 (10.2\%) specimens respectively.

In common with previous reports [7,13,16,19,28-31,38,39], our data confirmed the prognostic value of the IASLC/ ATS/ERS histologic classification, along with LVI, by logrank test. The 5-year RFS of lepidic predominant was 94.9\%; papillary predominant, 91.9\%; acinar predominant, $83.1 \%$; solid predominant, $67.4 \%$, and micropapillary predominant, $57.6 \%$. To gain more statistical power, previous studies combined subtype of similar prognosis to construct a two-tiered or three-tiered grading scheme. However, difference remains regarding the designation of papillary predominant adenocarcinomas. Interestingly, most studies on Asian patients grouped this subtype into lower- or intermediate-grade $[16,19,28,30,31]$, while most studies from western countries, grouped it into the highgrade group [27,29] except that by Yoshizawa et al. [28]. Comparison of these two grouping schemes on our cohort favored the former way of grouping (Figure 2, $P=0.005$ versus $P=0.181$ ), suggesting that the behaviors of papillary predominant subtype may have ethnical differences. This hypothesis can be supported by the findings in Asian patients of the association between EGFR mutation and papillary predominant adenocarcinomas $[39,40]$, but not in an Australian cohort [27].

The observation that new histologic subtype grouping remained the only risk factor for recurrence in patients of T1aN0M0 disease on multivariate Cox regression, and reported correlation of clinicopathologic variables with histologic subtypes, promoted us to investigate the relationship of these variables with subtype groupings. We chose low-grade or high-grade as binary dependent

Table 3 Correlation between clinicopathologic factors and high-grade adenocarcinoma group

\begin{tabular}{lccc}
\hline Variables & $\begin{array}{c}\text { Univariate } \\
\text { logistic, } \boldsymbol{P}\end{array}$ & $\begin{array}{c}\text { Multivariate logistic, } \\
\text { OR (95\% Cl) }\end{array}$ & $\boldsymbol{P}$ \\
\hline Age & 0.195 & & \\
Sex & 0.036 & $2.214(1.050$ to 4.668) & 0.037 \\
Smoking history & 0.469 & & \\
Tumor size & 0.884 & & \\
LVI & 0.070 & $2.091(0.938$ to 4.662) & 0.071 \\
Histological grading & 0.225 & & \\
\hline
\end{tabular}

Abbreviations: $\mathrm{Cl}$ confidence interval, $L V I$ lymphovascular invasion, $O R$ odds ratio. 
variables instead of each histologic subtype, for the reason that the present study focused on recurrence risks, which are more significantly related to subtype groupings. The correlation analysis confirmed the association of male gender and presence of LVI (borderline significant) with high-grade group (Table 3). Other researchers have reported similar associations. Hung et al. found that the lepidic predominant subtype is associated with less smoking exposure, smaller tumor size, absence of LVI, and well/moderately differentiated histologic grade, while the high-grade group member, solid predominant, is associated with male gender, smoking exposure, larger tumor size, and poorly differentiated histologic grade [19]. Yanagawa and colleagues reported higher frequency of smokers in solid predominant than in other subtypes [16]. Our results, along with these observations, suggested that these clinicopathologic variables, such as gender, smoking history and LVI, might not be independent prognostic factors, which may challenge the independency of these prognostic factors, such as female gender [7].

The local infiltration ability and metastatic potential of solid- and micropapillary predominant subtypes in the high-grade group, may explain the increased risk of recurrence. A recently published comparison of small $(\leq 2 \mathrm{~cm})$ adenocarcinoma patients who underwent sublobar resection versus lobectomy found that tumors with $\geq$ 5\% micropapillary component had more locoregional recurrences after limited resection, especially those with small surgical margins, but not in cases who underwent lobectomies [35]. The authors suggested a greater capacity for local infiltration of micropapillary subtype. Likewise, a study of adenocarcinomas with N2 metastasis suggested greater metastatic potential of micropapillary and solid predominant subtypes, even though they may not be the predominant subtype [27]. In a study of adenocarcinoma of post-operative adenocarcinomas at all stages, Russell reported the highest incidence of N2 metastases and invasion of lymphovascular spaces and visceral pleura for micropapillary predominant adenocarcinoma [20]. Indirect evidence also comes from a subtyping analysis of stages I to IV adenocarcinomas, which showed the highest rate of nodal metastases was for micropapillary predominant subtype (76\%), followed by solid predominant (51\%), whereas for lepidic, the rate was only 7\% [29]. However, with respect to prognosis, the predominant subtype was the main determinant $[27,29]$.

There is growing interest in considering sublobar resection for early-stage lung cancer. To date, limited evidence only supports the use of sublobar resection for subsolid lesions, a radiologic feature of preinvaisve or less invasive tumors [5,41]. Histologic subtypes of adenocarcinoma according to IASLC/ATS/ERS classification also stratifies invasiveness and may have potential implication for selecting limited resection histologically, as suggested by
Nitadori [35]. However, the accuracy of reporting adenocarcinoma subtypes on frozen section is still an open question.

We acknowledge several limitations of our retrospective study, which has a relatively small cohort of patients with sub-optimal follow-up periods. The fact that even indolent ground-glass opacity lesions can develop local recurrence more than five years after resection [42] implied the necessity of very long follow-up for these very early-staged cases. Moreover, not all recurrences were biopsy-confirmed, which is more accurate than radiologic evidence.

\section{Conclusions}

Our results showed that the solid- and micropapillary predominant subtype of IASLC/ATS/ERS classification remains the only risk factor for post-operative recurrence of T1aNOM0 adenocarcinomas, suggesting that they can be indicators of aggressive tumor behaviors. We agree with the proposal by Warth et al. that a tumor grading system based on the predominant pattern might assist clinical decisionmaking for pulmonary adenocarcinoma management [29].

\section{Abbreviations}

AIS: adenocarcinoma in situ; CT: computed tomography; EGFR: epidermal growth factor receptor; GGO: ground-glass opacity; H\&E: hematoxylin and eosin; HR: hazard ratio; IASLC/ATS/ERS: International Association for the Study of Lung Cancer, American Thoracic Society, and European Respiratory Society; LVI: lymphovascular invasion; MIA: minimally invasive adenocarcinoma; NSCLC: non-small cell lung cancer; OR: odds ratio; PET: positron emission tomography; RFS: recurrence-free survival; PET: positron emission tomography; VPI: visceral pleural invasion.

\section{Competing interests}

The authors declare that they have no competing interests.

\section{Authors' contributions}

FY and JW contributed equally to this work: both of them designed the study and wrote the whole article. KC and XL participated in the design of the study and carried out the statistics. DB and KS as pathologists re-classified all the adenocarcinoma specimens. KC and YL reviewed patients' records and collected data. All authors read and approved the final manuscript.

\section{Authors' information}

FY, KC and XL are staff members of Department of Thoracic Surgery, Peking University People's Hospital. YL is a PhD student of Peking University Health Science Center. KS and DB are staff members of Department of Pathology, Peking University People's Hospital.

\section{Author details}

${ }^{1}$ Department of Thoracic Surgery, Peking University People's Hospital, 11 Xizhimen Nan Ave, Beijing 100044, China. 'Department of Pathology, Peking University People's Hospital, 11 Xizhimen Nan Ave, Beijing 100044, China.

Received: 22 September 2013 Accepted: 2 September 2014 Published: 13 September 2014

\section{References}

1. Siegel R, Naishadham D, Jemal A: Cancer statistics, 2013. CA Cancer J Clin 2013, 63:11-30.

2. Alberg AJ, Brock MV, Ford JG, Samet JM, Spivack SD: Epidemiology of lung cancer: diagnosis and management of lung cancer, 3rd ed: American College of Chest Physicians evidence-based clinical practice guidelines. Chest 2013, 143:e1S-e29S.

3. Field JK, Oudkerk M, Pedersen JH, Duffy SW: Prospects for population screening and diagnosis of lung cancer. Lancet 2013, 382:732-741. 
4. Church TR, Black WC, Aberle DR, Berg CD, Clingan KL, Duan F, Fagerstrom RM, Gareen IF, Gierada DS, Jones GC, Mahon I, Marcus PM, Sicks JD, Jain A, Baum S: Results of initial low-dose computed tomographic screening for lung cancer. N Engl J Med 2013, 368:1980-1991.

5. Howington JA, Blum MG, Chang AC, Balekian AA, Murthy SC: Treatment of stage I and II non-small cell lung cancer: diagnosis and management of lung cancer, 3rd ed: American College of Chest Physicians evidence-based clinical practice guidelines. Chest 2013, 143:e278S-e313S.

6. Rami-Porta R, Ball D, Crowley J, Giroux DJ, Jett J, Travis WD, Tsuboi M, Vallieres E, Goldstraw P: The IASLC Lung Cancer Staging Project: proposals for the revision of the T descriptors in the forthcoming (seventh) edition of the TNM classification for lung cancer. J Thorac Oncol 2007, 2:593-602.

7. Zhang J, Wu J, Tan Q, Zhu L, Gao W: Why do pathological stage IA lung adenocarcinomas vary from prognosis?: a clinicopathologic study of 176 patients with pathological stage IA lung adenocarcinoma based on the IASLC/ATS/ERS classification. J Thorac Oncol 2013, 8:1196-1202.

8. Sakurai H, Asamura H, Goya T, Eguchi K, Nakanishi Y, Sawabata N, Okumura M, Miyaoka E, Fujii Y: Survival differences by gender for resected non-small cell lung cancer: a retrospective analysis of 12,509 cases in a Japanese Lung Cancer Registry study. J Thorac Oncol 2010, 5:1594-1601.

9. Park SY, Lee JG, Kim J, Bae MK, Lee CY, Kim DJ, Chung KY: The influence of smoking intensity on the clinicopathologic features and survival of patients with surgically treated non-small cell lung cancer. Lung Cancer 2013, 81:480-486.

10. Sakai T, Tsushima T, Kimura D, Hatanaka R, Yamada Y, Fukuda I: A clinical study of the prognostic factors for postoperative early recurrence in patients who underwent complete resection for pulmonary adenocarcinoma. Ann Thorac Cardiovasc Surg 2011, 17:539-543.

11. Barletta JA, Yeap BY, Chirieac LR: Prognostic significance of grading in lung adenocarcinoma. Cancer 2010, 116:659-669.

12. Oyama M, Miyagi Maeshima A, Tochigi N, Tsuta K, Kawachi R, Sakurai H, Watanabe $\mathrm{S}$, Asamura $\mathrm{H}$, Tsuda $\mathrm{H}$ : Prognostic impact of pleural invasion in 1,488 patients with surgically resected non-small cell lung carcinoma. Jpn J Clin Oncol 2013, 43:540-546.

13. Tao H, Hayashi T, Sano F, Takahagi A, Tanaka T, Matsuda E, Okabe K: Prognostic impact of lymphovascular invasion compared with that of visceral pleural invasion in patients with pN0 non-small-cell lung cancer and a tumor diameter of $2 \mathrm{~cm}$ or smaller. J Surg Res 2013, 185:250-254.

14. Strano S, Lupo A, Lococo F, Schussler O, Loi M, Younes M, Bobbio A, Damotte D, Regnard JF, Alifano M: Prognostic significance of vascular and lymphatic emboli in resected pulmonary adenocarcinoma. Ann Thorac Surg 2013, 95:1204-1210.

15. Matsuguma H, Oki I, Nakahara R, Suzuki H, Kasai T, Kamiyama Y, Igarashi S, Mori K, Endo S, Yokoi K: Comparison of three measurements on computed tomography for the prediction of less invasiveness in patients with clinical stage I non-small cell lung cancer. Ann Thorac Surg 2013, 95:1878-1884

16. Yanagawa N, Shiono S, Abiko M, Ogata SY, Sato T, Tamura G: New IASLC/ATS/ ERS classification and invasive tumor size are predictive of disease recurrence in stage I lung adenocarcinoma. J Thorac Oncol 2013, 8:612-618.

17. David E, Thall PF, Kalhor N, Hofstetter WL, Rice DC, Roth JA, Swisher SG, Walsh GL, Vaporciyan AA, Wei C, Mehran RJ: Visceral pleural invasion is not predictive of survival in patients with lung cancer and smaller tumor size. Ann Thorac Surg 2013, 95:1872-1877. Discussion 1877.

18. Travis WD, Brambilla E, Noguchi M, Nicholson AG, Geisinger KR, Yatabe $Y$ Beer DG, Powell CA, Riely GJ, Van Schil PE, Garg K, Austin JH, Asamura H, Rusch WW, Hirsch FR, Scagliotti G, Mitsudomi T, Huber RM, Ishikawa Y, Jett J, Sanchez-Cespedes M, Sculier JP, Takahashi T, Tsuboi M, Vansteenkiste J, Wistuba I, Yang PC, Aberle D, Brambilla C, Flieder D, et al: International Association for the Study of Lung Cancer/American Thoracic Society/ European Respiratory Society international multidisciplinary classification of lung adenocarcinoma. J Thorac Oncol 2011, 6:244-285.

19. Hung JJ, Jeng WJ, Chou TY, Hsu WH, Wu KJ, Huang BS, Wu YC: Prognostic value of the new International Association for the Study of Lung Cancer/ American Thoracic Society/European Respiratory Society lung adenocarcinoma classification on death and recurrence in completely resected stage I lung adenocarcinoma. Ann Surg 2013, 258:1079-1086.

20. Russell PA, Wainer Z, Wright GM, Daniels M, Conron M, Williams RA: Does lung adenocarcinoma subtype predict patient survival?: a clinicopathologic study based on the new International Association for the Study of Lung Cancer/American Thoracic Society/European
Respiratory Society international multidisciplinary lung adenocarcinoma classification. J Thorac Oncol 2011, 6:1496-1504.

21. Igai H, Matsuura N, Tarumi S, Chang SS, Misaki N, Go T, Ishikawa S, Yokomise $\mathrm{H}$ : Clinicopathological study of p-T1aNOM0 non-small-cell lung cancer, as defined in the seventh edition of the TNM classification of malignant tumors. Eur J Cardiothorac Surg 2011, 39:963-967.

22. Igai H, Matsuura N, Tarumi S, Chang SS, Misaki N, Ishikawa S, Yokomise H: Prognostic factors in patients after lobectomy for p-T1aNOMO adenocarcinoma. Eur J Cardiothorac Surg 2012, 41:603-606.

23. Silvestri GA, Gonzalez AV, Jantz MA, Margolis ML, Gould MK, Tanoue LT, Harris LJ, Detterbeck FC: Methods for staging non-small cell lung cancer: diagnosis and management of lung cancer, 3rd ed: American College of Chest Physicians evidence-based clinical practice guidelines. Chest 2013, 143:e211S-e250S.

24. Schiller JH, Harrington D, Belani CP, Langer C, Sandler A, Krook J, Zhu J, Johnson DH: Comparison of four chemotherapy regimens for advanced non-small-cell lung cancer. N Engl J Med 2002, 346:92-98.

25. Maemondo M, Inoue A, Kobayashi K, Sugawara S, Oizumi S, Isobe H, Gemma A, Harada M, Yoshizawa H, Kinoshita I, Fujita Y, Okinaga S, Hirano H, Yoshimori K, Harada T, Ogura T, Ando M, Miyazawa H, Tanaka T, Saijo Y, Hagiwara K, Morita S, Nukiwa T: Gefitinib or chemotherapy for non-smallcell lung cancer with mutated EGFR. N Engl J Med 2010, 362:2380-2388.

26. Matsuo K, Ito H, Yatabe Y, Hiraki A, Hirose K, Wakai K, Kosaka T, Suzuki T, Tajima K, Mitsudomi T: Risk factors differ for non-small-cell lung cancers with and without EGFR mutation: assessment of smoking and sex by a case-control study in Japanese. Cancer Sci 2007, 98:96-101.

27. Russell PA, Barnett SA, Walkiewicz M, Wainer Z, Conron M, Wright GM, Gooi J, Knight S, Wynne R, Liew D, John T: Correlation of mutation status and survival with predominant histologic subtype according to the new IASLC/ATS/ERS lung adenocarcinoma classification in stage III (N2) patients. J Thorac Oncol 2013, 8:461-468.

28. Yoshizawa A, Motoi N, Riely GJ, Sima CS, Gerald WL, Kris MG, Park BJ, Rusch WW, Travis WD: Impact of proposed IASLC/ATS/ERS classification of lung adenocarcinoma: prognostic subgroups and implications for further revision of staging based on analysis of 514 stage I cases. Mod Pathol 2011, 24:653-664.

29. Warth A, Muley T, Meister M, Stenzinger A, Thomas M, Schirmacher P, Schnabel PA, Budczies J, Hoffmann H, Weichert W: The novel histologic International Association for the Study of Lung Cancer/American Thoracic Society/European Respiratory Society classification system of lung adenocarcinoma is a stage-independent predictor of survival. J Clin Oncol 2012, 30:1438-1446.

30. Gu J, Lu C, Guo J, Chen L, Chu Y, Ji Y, Ge D: Prognostic significance of the IASLC/ATS/ERS classification in Chinese patients - a single institution retrospective study of 292 lung adenocarcinoma. J Surg Oncol 2013, 107:474-480.

31. Woo T, Okudela K, Mitsui H, Tajiri M, Yamamoto T, Rino Y, Ohashi K, Masuda M: Prognostic value of the IASLC/ATS/ERS classification of lung adenocarcinoma in stage I disease of Japanese cases. Pathol Int 2012, 62:785-791.

32. Nitadori J, Colovos C, Kadota K, Sima CS, Sarkaria IS, Rizk NP, Rusch WW, Travis WD, Adusumilli PS: Visceral pleural invasion does not affect recurrence or overall survival among patients with lung adenocarcinoma $</=2 \mathrm{~cm}$ : a proposal to reclassify T1 lung adenocarcinoma. Chest 2013, 144:1622-1631.

33. Yoshida J, Nagai K, Asamura H, Goya T, Koshiishi Y, Sohara Y, Eguchi K, Mori M, Nakanishi Y, Tsuchiya R, Miyaoka E: Visceral pleura invasion impact on non-small cell lung cancer patient survival: its implications for the forthcoming TNM staging based on a large-scale nation-wide database. J Thorac Oncol 2009, 4:959-963.

34. Riquet M, Assouad J, Bagan P, Foucault C, Le Pimpec Barthes F, Dujon A, Danel C: Skip mediastinal lymph node metastasis and lung cancer: a particular N2 subgroup with a better prognosis. Ann Thorac Surg 2005, 79:225-233.

35. Nitadori J, Bograd AJ, Kadota K, Sima CS, Rizk NP, Morales EA, Rusch WW, Travis WD, Adusumilli PS: Impact of micropapillary histologic subtype in selecting limited resection vs lobectomy for lung adenocarcinoma of 2 cm or smaller. J Natl Cancer Inst 2013, 105:1212-1220.

36. Nitadori J, Bograd AJ, Morales EA, Rizk NP, Dunphy MP, Sima CS, Rusch WW, Adusumilli PS: Preoperative consolidation-to-tumor ratio and SUVmax stratify the risk of recurrence in patients undergoing limited resection for lung adenocarcinoma $</=2 \mathrm{~cm}$. Ann Surg Oncol 2013, 20:4282-4288 
37. Warth A, Cortis J, Fink L, Fisseler-Eckhoff A, Geddert H, Hager T, Junker $K$, Kayser G, Kitz J, Langer F, Morresi-Hauf A, Ott G, Petersen I, Stenzinger A, Soltermann A, Ting S, Tischler V, Vollmer E, Schnabel PA, Weichert W: Training increases concordance in classifying pulmonary adenocarcinomas according to the novel IASLC/ATS/ERS classification. Virchows Arch 2012, 461:185-193.

38. Kadota K, Colovos C, Suzuki K, Rizk NP, Dunphy MP, Zabor EC, Sima CS, Yoshizawa A, Travis WD, Rusch WW, Adusumilli PS: FDG-PET SUVmax combined with IASLC/ATS/ERS histologic classification improves the prognostic stratification of patients with stage I lung adenocarcinoma. Ann Surg Oncol 2012, 19:3598-3605.

39. Yoshizawa A, Sumiyoshi S, Sonobe M, Kobayashi M, Fujimoto M, Kawakami F, Tsuruyama T, Travis WD, Date H, Haga H: Validation of the IASLC/ATS/ ERS lung adenocarcinoma classification for prognosis and association with EGFR and KRAS gene mutations: analysis of 440 Japanese patients. J Thorac Oncol 2013, 8:52-61.

40. Sun PL, Seol H, Lee HJ, Yoo SB, Kim H, Xu X, Jheon S, Lee CT, Lee JS, Chung $\mathrm{JH}$ : High incidence of EGFR mutations in Korean men smokers with no intratumoral heterogeneity of lung adenocarcinomas: correlation with histologic subtypes, EGFR/TTF-1 expressions, and clinical features. J Thorac Oncol 2012, 7:323-330.

41. Naidich DP, Bankier AA, MacMahon H, Schaefer-Prokop CM, Pistolesi M, Goo JM, Macchiarini P, Crapo JD, Herold CJ, Austin JH, Travis WD: Recommendations for the management of subsolid pulmonary nodules detected at $\mathrm{CT}$ : a statement from the Fleischner Society. Radiology 2013, 266:304-317.

42. Nakao M, Yoshida J, Goto K, Ishii G, Kawase A, Aokage K, Hishida T, Nishimura M, Nagai K: Long-term outcomes of 50 cases of limited-resection trial for pulmonary ground-glass opacity nodules. J Thorac Oncol 2012, 7:1563-1566.

doi:10.1186/1477-7819-12-285

Cite this article as: Yang et al:: Risk factors of recurrence for resected T1aNOM0 invasive lung adenocarcinoma: a clinicopathologic study of 177 patients. World Journal of Surgical Oncology 2014 12:285.

\section{Submit your next manuscript to BioMed Central and take full advantage of:}

- Convenient online submission

- Thorough peer review

- No space constraints or color figure charges

- Immediate publication on acceptance

- Inclusion in PubMed, CAS, Scopus and Google Scholar

- Research which is freely available for redistribution 